\title{
Critical discourse analysis of synchronic and diachronic variation in institutional turn-allocation
}

\author{
Michael A. Shepherd \\ Arizona State University \\ masheph2@asu.edu
}

\section{Introduction}

Sociolinguistic research in the tradition of Labov (1966, et seq.) has tended to focus on phonological and morphosyntactic variation, with discursive variation receiving relatively little attention (though see, e.g., Hasan 2004). Nevertheless, just as the incorporation of qualitative methods, such as ethnography (e.g., Eckert 1989, et seq.), has advanced sociolinguistics, the incorporation of quantitative variationist methods into the (traditionally qualitative) study of language-in-interaction can enhance discourse analysis. This is particularly evident in critical analyses of institutional discourse, such as Conley and O’Barr's (1990) research in small claims courts, which found (qualitatively) that most litigants use one of two discursive strategies in presenting their cases and (quantitatively) that users of the more successful strategy were, overwhelmingly, educated men, a finding that the authors attributed to gendered differences in the distribution of opportunities to acquire "powerful” discourses.

This paper explores discursive variation in another institutional setting - the classroom-examining synchronic and diachronic variation in the discursive strategies teachers use in allocating turns at talk to individual students. Teachers use two main turn-allocation strategies: “individual nominations” and “invitations to bid” (Mehan 1979), each of which will be discussed in turn.

\section{Individual nominations}

In an individual nomination, the teacher poses a question or otherwise elicits a student response and then selects a specific student to provide that respond. This is illustrated in (1):

\section{TEACHER: What time is it, Susan?}

SUSAN: $\quad$ Three o'clock.

(adapted from Sinclair \& Coulthard 1975: 37)

The available data suggest that individual nominations were the primary floor-allocation method in U.S. classrooms in the 1970s, accounting for over 70 percent of teacher-initiated interactions (Mehan et al. 1976, Griffin \& Humphrey 1978). The predominance of this floor-allocation method has been attributed to teachers' goal of equitably distributing turns at talk and the fact that individual nominations make it easy to ensure that every student takes such a turn (Griffin \& Humphrey 1978: 88). Despite the enduring importance of this objective (see, e.g., Fennema 1990, Secada et al. 1995), more recent research suggests that invitations to bid (discussed in the next section) have since become the predominant floor-allocation method in many classrooms (Lemke 1990: 7).

\section{Invitations to bid}

An invitation to bid involves the teacher's posing a question or otherwise eliciting a student response and then soliciting students to make themselves known (e.g., by raising a hand; Sahlström 2002) if they would like to give the response, after which the teacher nominates one of the bidders. The example in (2) illustrates this:

(2) TEACHER: Who can tell me what time it is.

STUDENTS: [Raise hands]

TEACHER: Susan?

SUSAN: Three o'clock. 
As was mentioned in the last section, the available research suggests that invitations to bid have replaced individual nominations as the predominant floor-allocation method in U.S. classrooms (Lemke 1990, p. 7).

Overview

This paper first confirms that a shift to invitations to bid has in fact taken place, through a quantitative analysis of the discursive strategies teachers use in allocating turns at talk in the 2008 SoCal classroom corpus (see the Method section). Qualitative analyses_of the adjacency pair structure (Levinson 1983) and discursive functions of each strategy — suggest a motivation for this shift. Finally, additional quantitative analyses reveal the impact of this shift on the distribution of turns at talk.

\section{Method}

The SoCal classroom corpus consists of detailed transcriptions of eight reading and math lessonsapproximately 4.5 hours of interaction-video-recorded in 2008 in three third-grade classes (students ages 8-9) at a diverse Southern California public elementary school located in a lower-middle class suburban neighborhood. ${ }^{1}$

The three teachers in the corpus are White females. At the time of recording, one was in her 11th year of teaching, one in her 13th, and one in her 24th. Of the 20 students in each class, approximately half are White and half are Hispanic, with roughly equal numbers of boys and girls and just under 42 percent receiving free or reduced-price meals, all of which was representative of the school at that time.

\section{Results and discussion}

\section{Quantitative analysis of the relative prevalence of each strategy}

There are 262 instances in the SoCal classroom corpus where a teacher allocates a turn at talk to an individual student. Of these, $11.5 \%(n=30)$ are individual nominations-where the teacher extends a response opportunity and selects a student to respond without that student's having bid—and 88.5\% ( $n=$ 232) are invitations to bid-where the teacher extends a response opportunity and solicits students to make themselves known (e.g., by raising a hand) if they want a turn at talk, then nominates one of the bidders.

This stands in stark contrast to the results of comparable analyses from the 1970s, which found that individual nominations (which made up a mere 11.5\% of turn allocations in the SoCal classroom corpus) constituted over 70\% of all teacher-initiated interactions (Mehan et al. 1976, Griffin \& Humphrey 1978). This supports Lemke's (1990, p. 7) impression that invitations to bid have become the predominant floorallocation method used in classrooms.

Discussion of these findings with those involved in the study provides further support for the notion of a shift in discursive practices, as educators are apparently well aware of the move from individual nominations to invitations to bid and see it as part of a larger, ostensibly positive move away from the ‘authoritarian’ classroom of old and toward a more ‘egalitarian’ model (cf. Cazden 2001).

Qualitative analysis of the adjacency-pair structure of each strategy

Analysis of the adjacency-pair structure (see Levinson 1983, p. 332ff) of individual nominations and invitations to bid provides addition insight into the advantages and disadvantages of each discursive strategy. Individual nominations are comprised of two turns that can be analyzed straightforwardly as forming a single adjacency pair. The first pair part, spoken by the teacher, includes a cue that elicits a student contribution and a nomination of a specific student to make that contribution. The second pair part, spoken by the nominated student, consists of that student's contribution.

\footnotetext{
${ }^{1}$ Two reading and two math lessons were recorded in one of the three classes, and one reading and one math lesson were recorded in each of the other two.
} 
Invitations to bid, by contrast, are made up of four turns: the teacher's indicating that a student contribution is sought; some number of students' bidding to contribute; the teacher's nomination of one of the bidders; and the nominated student's contribution. Given this, two adjacency-pair analyses are possible. One analysis treats the first and fourth turns as forming a cue-response adjacency pair that is analogous to the individual-nomination pair, and treats the second and third turns as forming a bidding-nomination insertion sequence, as illustrated in (3).

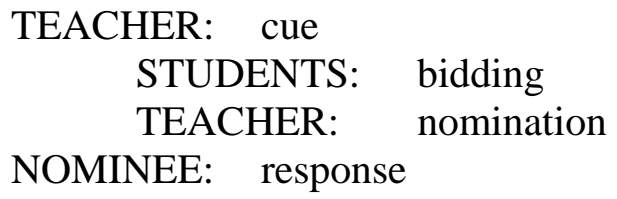

However, this analysis seems incorrect for two reasons. First of all, insertion sequences are typically optional, but bidding is clearly not optional in an invitation to bid. When students respond to an invitation to bid by answering (without bidding and waiting to be nominated), they are ignored, if not reprimanded (Mehan 1979, p. 111, Lemke 1990, p. 70, Mercer 1992). Moreover, when an invitation to bid receives no response from a class, the teacher's reaction does not index the failure of one or more students to answer but the failure of anyone to bid. The fact that providing an answer in response to an invitation to bid is unacceptable, combined with the fact that what such elicitations make interactionally relevant is not responding but bidding, suggests that bidding cannot be part of an insertion sequence.

The other analysis treats the first and second turns as forming a cue-bidding presequence and the third and fourth as forming a nomination-response main sequence, as illustrated in (4).

$$
\begin{array}{ll}
\text { TEACHER: } & \text { cue } \\
\text { STUDENTS: } & \text { bidding } \\
\text { TEACHER: } & \text { nomination } \\
\text { NOMINEE: } & \text { response }
\end{array}
$$

This analysis accounts straightforwardly for the facts discussed above, namely, that an answer immediately following a cue is unacceptable, and that bidding is interactionally relevant and its absence marked. Bidding is interactionally relevant because it constitutes not the first part of a bidding-nomination insertion sequence but the second part of a cue-bidding presequence.

The adjacency-pair analysis in (4) also explains an important interactional advantage of invitations to bid over individual nominations. Nominating a student without his/her having bid can be risky, as the nominee may be unprepared to respond (McHoul 1978), whereas students who bid are more likely to have a response (Griffin \& Humphrey 1978: 90). In terms of the analysis in (4), invitations to bid reduce the risk of calling on an unprepared student by introducing a cue-bidding presequence before the main nominationresponse sequence. Just as other presequences, such as pre-invitations and pre-requests, help avoid other dispreferred sequences, such as rejection and denial, respectively, (Liddicoat 2011), this cue-bidding presequence helps teachers avoid dispreferred (incorrect or inappropriate) responses by allowing them to identify which students are prepared to respond.

\section{Quantitative analysis of the impact of invitations to bid on the distribution of turns at talk}

Analyses of classroom discourse from the 1970s indicate that teachers of that era used primarily individual nominations because they saw it as their responsibility to ensure that turns at talk were distributed equitably (Griffin \& Humphrey 1978: 88). Using primarily invitations to bid shifts this responsibility to students and ties the distribution of turns at talk to student initiative, putting students who are ill disposed to take the required initiative at a serious disadvantage. A linear regression analysis of data 
from the SoCal classroom corpus confirms that the number of times a student chooses to bid (which ranges from an average of 2 per lesson for the least outgoing students to an average of 18 per lesson for the most outgoing) significantly predicts the number of turns he/she has at talk, $\beta=.84, t(28)=8.16, p<.001$.

\section{Conclusions}

Blending quantitative variationist methods with traditional qualitative discourse analysis can greatly enhance the study of language in interaction. In the present study, this mixing of methods not only revealed a shift in the relative prevalence of the discursive strategies teachers use in allocating turns at talk, but helped explain why this shift has taken place and showed how it puts less-outgoing students at a disadvantage. This disadvantage ultimately means fewer opportunities to practice not only advancing their ideas but accessing and using discursive power (cf. Conley \& O’Barr 1990).

\section{References}

Cazden, Courtney B. 2001. Classroom discourse: The language of teaching and learning, 2nd edn. Portsmouth, NH: Heinemann.

Conley, John M. \& William M. O’Barr. 1990. Rules versus relationships: The ethnography of legal discourse. Chicago, IL: University of Chicago Press.

Eckert, Penelope. 1989. Jocks and burnouts: Social categories and identity in the high school. New York, NY: Teachers College Press.

Fennema, Elizabeth. 1990. Justice, equity, and mathematics education. In Elizabeth Fennema \& Gilah C. Leder (eds.), Mathematics and gender, 1-9. New York, NY: Teachers College Press.

Griffin, Peg \& Frank Humphrey. 1978. Talk and task at lesson time. In Roger W. Shuy \& Peg Griffin (eds.), Children's functional language and education in the early years. Final report to Carnegie Corporation.

Hasan, Ruqaiya. 2004. Analysing discursive variation. In Lynne Young \& Claire Harrison (eds.), Systemic functional linguistics and critical discourse analysis studies in social change, 15-52. New York, NY: Continuum.

Labov, William. 1966. The social stratification of English in New York City. Washington, DC: Center for Applied Linguistics.

Lemke, Jay L. 1990. Talking science: Language, learning, and values. Norwood, NJ: Ablex.

Levinson, Stephen C. 1983. Pragmatics. New York, NY: Cambridge University Press.

Liddicoat, Anthony L. 2011. Introduction to conversation analysis, 2nd edn. New York, NY: Continuum.

McHoul, Alexander W. 1978. The organization of turns at formal talk in the classroom. Language in Society 7(2). 183-213.

Mehan, Hugh. 1979. Learning lessons: Social organization in the classroom. Cambridge, MA: Harvard University Press.

Mehan, Hugh, Courtney B. Cazden, LaDonna Coles, Sue Fisher \& Nick Maroules. 1976. The social organization of classroom lessons. CHIP Report 67. La Jolla, CA: University of California, San Diego, Department of Psychology, Center for Human Information Processing.

Mercer, Neil. 1992. Talk for teaching-and-learning. In Kate Norman (ed.), Thinking voices: Work of the National Oracy Project, 215-223. London, UK: Hodder \& Stoughton (for the National Curriculum Council).

Sahlström, Fritjof. 2002. The interactional organization of hand raising in classroom interaction. Journal of Classroom Interaction 37(2). 47-57.

Secada, Walter G., Elizabeth Fennema \& Lisa Byrd Adajian (eds.). 1995. New directions for equity in mathematics education. New York, NY: Cambridge University Press.

Sinclair, John McH. \& R. Malcolm Coulthard. 1975. Towards an analysis of discourse: The English used by teachers and pupils. London, UK: Oxford University Press. 